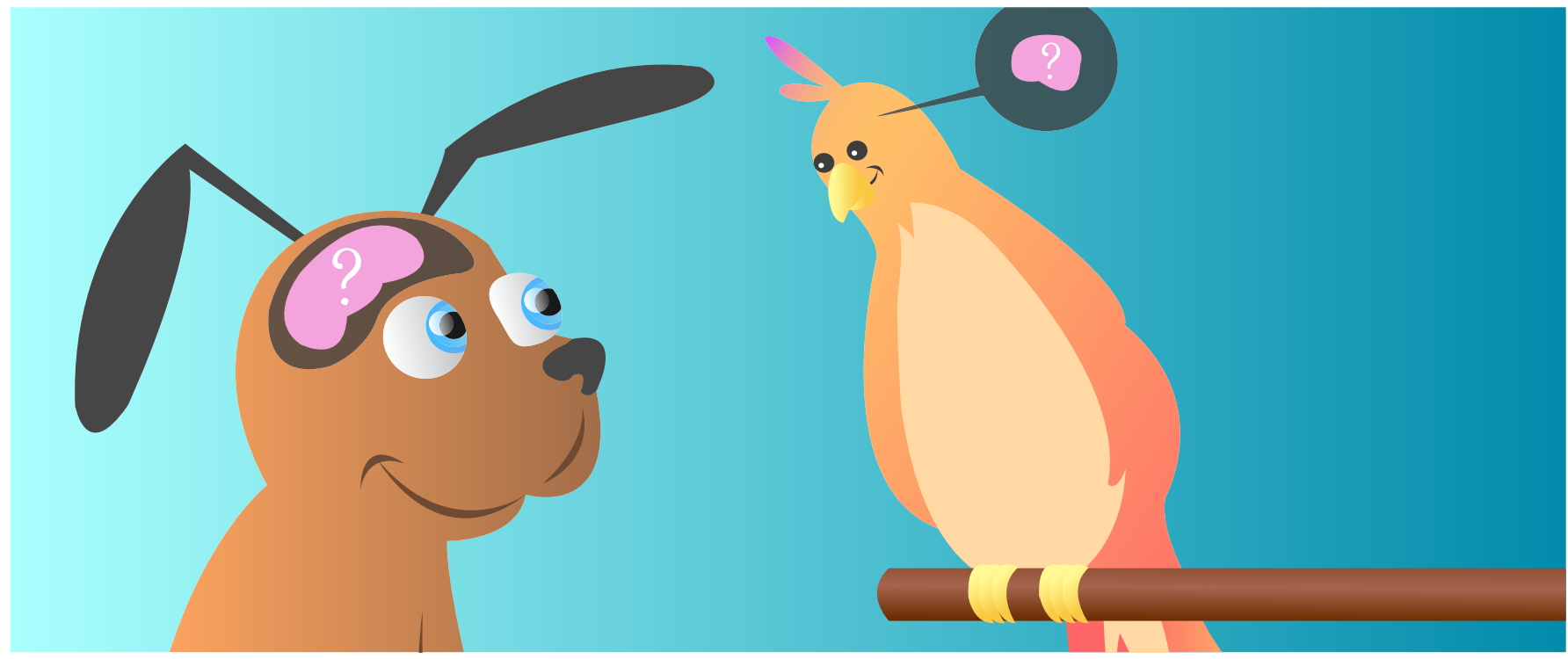

\title{
WHAT ARE DIFFERENT BRAINS MADE OF?
}

\section{Kleber Neves ${ }^{1 *}$, Felipe daCunha ${ }^{1}$ and Suzana Herculano-Houzel ${ }^{2}$}

${ }^{1}$ Programa de Pós-Graduação em Ciências Morfológicas, Instituto de Ciências Biomédicas, Universidade Federal do Rio de Janeiro, Rio de Janeiro, Brazil, ${ }^{2}$ Department of Psychology and Department of Biological Sciences, Vanderbilt University, Nashville, TN, USA

\section{REVIEWED BY:}

RIVERSIDE ELEMENTARY SCHOOL 9-10 YEARS OLD
The brain is the most complex organ that ever evolved. The brain controls important functions in the body like keeping your heartbeat and your breathing normal. It controls the movement of your eyes across the page as you read this, it makes sense of the ink on the page to form words, and it links these words with concepts in your memory and makes new concepts as you learn. And the brain was also the part of your body that made the decision to read this article in the first place. In different animals, brains are very different. There are large and small brains, smooth and wrinkled brains, brains with some parts larger than others. How are these brains built? How did they come to be so different from each other-and why does that matter?

\section{ANIMALS SHARE AN EVOLUTIONARY HISTORY}

Not only humans have brains, of course. Almost all animals have a nervous system of some kind (only sponges do not). The brains of different animals are different in some ways but similar in many other ways. This is because all life on the planet shares a history: all animals evolved from common ancestors, so they inherited some of the characteristics from these ancestors. This is like a brother and a sister who are alike because they have the same parents, first 
cousins who have the same grandparents, second cousins who share greatgrandparents, and so on. All life shares a great-great-great-grandparent in the distant past.

We can use these similarities and differences between animals to put the animals together into groups. Two birds - say, an eagle and a parrot-have more in common than an eagle and a monkey. And they are closer relatives. In a family, this would be like saying that a brother is more like his sister than he is like his cousin. A brother and a sister have the same parents, but with their cousin they only share the same grandparents, further back. Still, all mammals have fur and produce milk to feed their young. Every bird has feathers and lays eggs. And these similarities between close relatives appear in their brains, too.

Each species has their different habits: a monkey jumps from branch to branch until it finds some fruit to eat, a bat flies around in the dark of the night between trees, a whale swims in the wide open ocean. Since the brains of these animals help them to do all these tasks, we would guess that their brains would be very different. But it turns out that the main parts of the brain and the connections within the brain are all pretty much the same for all mammals. This similarity in brain structure exists because of the evolutionary history that all these brains share.

In fact, if we put brains of different mammals next to each other, the similarities are easy to spot. Even though the brains vary (a lot) in their size and in their folds, they all have the same parts. All these brains have a cerebral cortex, a cerebellum, and a brain stem (see Figure 1B). Also, the same kinds of cells make up all brains: they are made of neurons, glial cells, and the cells that make the capillaries (small blood vessels) that bring blood into the brain (Figure 1A). Neurons transmit information to other neurons through their branches, across connections called synapses. Glial cells are of three kinds. Microglia are the immune system in the brain. Oligodendrocytes wrap the branches of the neurons and make information move faster from

FIGURE 1

A. All brains have two connected sides, called the right and left hemispheres.

In the figure, you see the inside of the right hemisphere of a human brain. The main colored parts are the cerebral cortex, the cerebellum, and the brainstem.
A

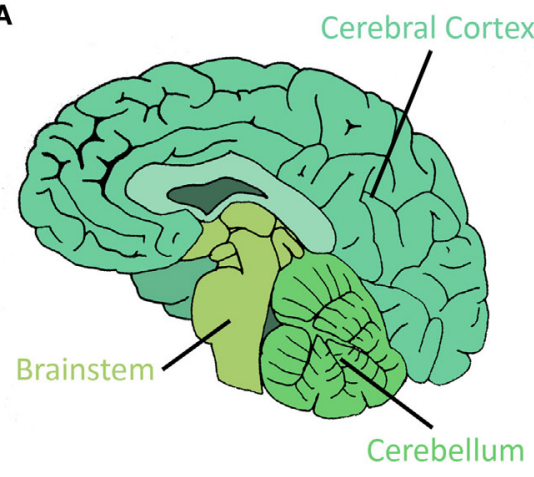

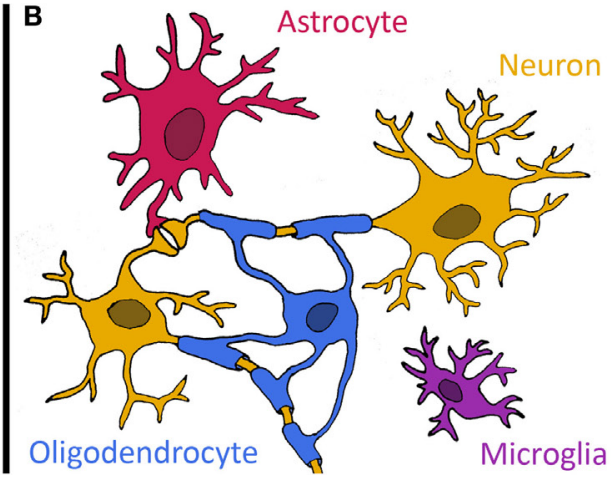

FIGURE 1 
FIGURE 1

\section{CONTINUED}

The cerebral cortex, the "thinking part" of the brain, is where things like speech, planning, emotions, and problemsolving take place. Depending on the species, the cerebral cortex can be smooth or full of folds (like ours, in the figure). The cerebellum looks like a small brain and also has folds. Keeping proper posture, balance and doing delicate, careful movements are all tasks involving the cerebellum. So are thinking and handling emotions. The brainstem is the region that connects the whole brain with the body, through several nerves and the spinal cord, and controls vital automatic movements such as breathing, digestion, heart rate, and blood pressure. B. Neurons (in gold) - they receive, process, and send information to other neurons. Axons (the "cables" from one neuron to another) are wrapped by oligodendrocyte cells (blue), which create a coating, much like the rubber around electric wires, that insulates axons and helps signals be conducted from one neuron to the next more quickly. Astrocytes (red) have lots of functions. Scientists thought, at first, that all astrocytes did was fill in the space between neurons, holding them apart and giving them something like a "skeleton" on the outside. But now, we know that astrocytes do much more: they feed neurons, control the formation of the contacts between neurons (the synapses) and how they

(CONTINUED) one neuron to the next. Astrocytes do a lot of things, keeping everything in order-from helping neurons make synapses to providing them with nutrients.

\section{IS THERE ONLY ONE RULE TO BUILD BRAINS?}

Even though the parts are the same, this does not mean that brains of the same size are built of the same amounts of each kind of cell. It is also not true that a bigger brain is always made of more cells than a smaller brain.

We can think about this with an example. Imagine that you receive two brains of the same weight but belonging to different species. This is what we see in Figure 2: a rhesus monkey brain and a capybara brain (a capybara is the largest rodent alive, it looks like a giant guinea pig). Both brains weigh about $80 \mathrm{~g}$. You would probably say the brains have the same number of neurons-and so would many scientists. Until about 10 years ago, most researchers expected brains of the same size to have the same number of neurons. They thought that there was only one "recipe" in nature for building brains, and that all brains were made the same way. That also meant that the bigger the brain, the more neurons it would have.

We now know that neither of these things is true. In 2005, one of us (Suzana) developed a new method that lets us count how many neurons make up a brain [1]. This method dissolves the brain into soup (Box 1), starting with a recently dead brain that has been treated with a chemical called paraformaldehyde (PFA) to make the cells more resistant (if the brain is not treated with PFA, you could damage it just by touching it). If you do not use the soup method and instead take a piece of a brain and count how many cells are there, you might count cells from a place in the brain that is full of neurons and then you would think that the whole brain has a lot of neurons. But the number of cells is not the same in all parts of the brain-some brain parts have more neurons, some have fewer. That is why we make brain soup: because then, all drops of "soup" have about the same number of cells once you stir the soup really well. Besides, since this soup contains each and every cell that made up the original part of the brain, or perhaps the whole brain (if you did not separate its parts first), then by looking under the microscope and counting the cells in just a little bit of the "soup" we can get a good idea of how many cells the whole brain has.

Let us take imaginary brains in our hands again, this time two primate brains, one twice the size of the other. How many neurons would the larger one have? Well, in this case, about twice the number of neurons of the smaller brain. Now, if brains were all built in the same way, with the same uniform recipes, we would see the same thing in rodents. So, if we took now two rodent brains, one brain twice as big as the other, we would expect the larger one to have twice as 
FIGURE 1

\section{CONTINUED}

function, control the concentration of many substances in the space outside the cells, and repair injuries. Finally, microglia (purple) detect and destroy strange cells and particles that do not belong in the brain, protecting it, like the immune system protects the rest of the body.

\section{RODENT}

\section{Group of small} mammals, known for their large front teeth. Mice and rats are rodents.

\section{PRIMATE}

The group of animals made up of humans, all apes and monkeys, from small lemurs to the largest, the gorilla.

\section{FIGURE 2}

Nature has different ways of adding neurons to primate and rodent brains as they change in size from one species to another. This means that when a rodent brain gets larger, it does not gain many neurons. In contrast, when a primate brain gets bigger, its number of neurons grows more or less in proportion to how much larger the brain is. many neurons as the smaller one. But if you do this with actual brains you will see that the larger rodent brain has fewer neurons than expected-less than twice as many neurons in a brain that is twice as large. This means rodents and primates have different rules for building brains. Most importantly, if you were to compare a largish primate brain (like the brain of a monkey) with a similarly largish rodent brain (like the brain of a capybara), you would find that the monkey brain has many more neurons than the rodent brain.

The different relationships between brain size and number of neurons for rodents and primates means that different recipes, or "rules," apply when these brains are built in nature. The rule for primates says "if you have 10 times as many neurons, you get a brain about 10 times as big." The rule for rodents says "if you have 10 times as many neurons, you get a brain that is 45 times larger." The different rules mean that rodent brains grow much faster than primate brains as they gain neurons. So, without knowing the rules are different, you would guess that a primate brain has fewer neurons than it actually has. But the truth is, there are many more neurons in a primate brain than in a rodent brain of the same size. To see this with real numbers for real brains, you can look at the examples in Figure 2.

\section{TESTING AND CHANGING RULES}

If you know the rule relating brain size to the number of neurons, you can predict how many neurons a brain of a certain size would have, according to that rule. The rules will also show what limits exist for building brains.

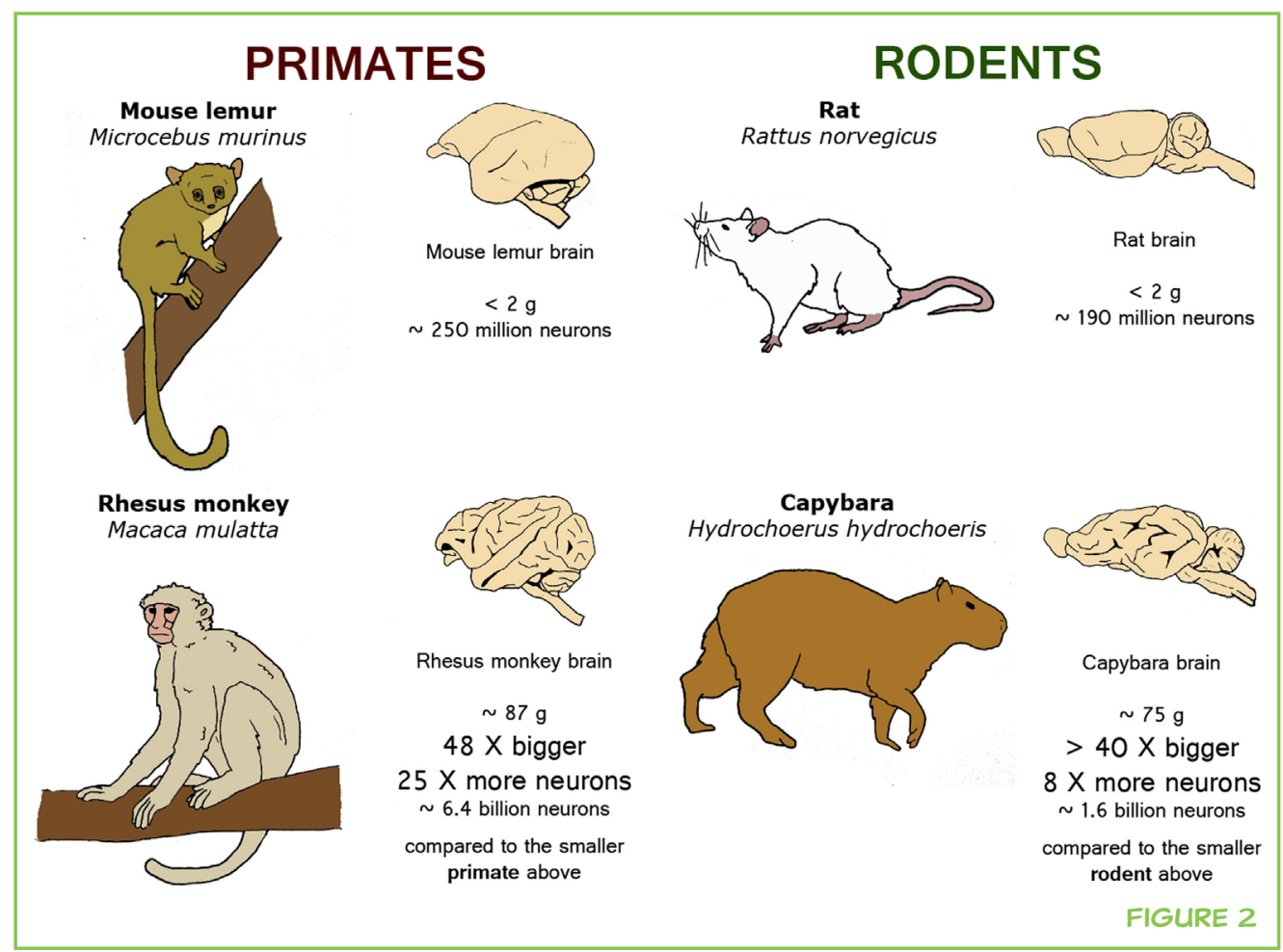




\section{INSECTIVORES}

A group of small mammals which eat insects. These are hedgehogs and moles. Also, the smallest mammal in the world-the Etruscan shrew, weighing $2 \mathrm{~g}-$ belongs to this group.

\section{CARNIVORES}

These are mammals known for hunting and eating meat. Dogs and cats fit here, but also lions, bears, and hyenas.

\section{MARSUPIALS}

These are the mammals with a pouch to carry their young. Most of them are from Australia. Kangaroos, opossums, and koalas are marsupials.

\section{CETACEANS}

Aquatic mammals, almost all living in the sea. Whales, dolphins, and porpoises.

\section{BOX 1 | HOW TO MAKE BRAIN SOUP.}

Here is the idea: we want to take a brain and destroy everything to make soup-except the nuclei of the cells that make up the brain. Because each brain cell has only one nuclei, if we find the number of nuclei, we find the number of cells that make up the brain.

Step 1: Put the brain in paraformaldehyde (PFA) for a few days. This process is called fixation. PFA will make the nuclei membranes stronger, so they won't break later.

Step 2: Separate the part of the brain that you want to know about. Then slice it into small pieces.

Step 3: Put the sliced brain tissue inside the "soup-maker glass." This tool is made of two pieces of glass, carefully built so that when one is inside the other the space between the glasses is very very small (search for "glass tissue grinder" on the web to see pictures).

Step 4: Add a detergent to help break up the tissue. Use a special detergent that won't destroy the nuclear membrane (remember, we want them preserved so we can count the nuclei in the soup).

Step 5: Move the inside glass up and down and rotate it, to break up the brain tissue. This is called fractionating. By rubbing these two pieces of the glass against each other, the friction breaks the brain pieces into smaller and smaller pieces, eventually leaving only the nuclei of the cells (which is what we count on the microscope). This is sort of like making juice: you press the brain against the glass, just like a fruit is pressed against the rotating juicer reamer to extract its juice.

To pick a familiar example, a generic primate brain of $1.5 \mathrm{~kg}$, just like our brain, should have 93 billion neurons, according to the primate rule. Our best estimate for how many neurons we have is 86 billion neurons, on average [2]. That is pretty close. What this tells us is that, well, we have a primate brain: we are that generic primate. In other words, as far as numbers of neurons go, our brains are not special compared to those of our closest relatives, the apes and monkeys. We have just as many neurons as a primate with our brain size should have. But because we are the primate with the biggest brain, we have the most neurons of any primate.

But what would things be like if we were rodents? What if, instead of a primate brain of $1.5 \mathrm{~kg}$, we had a rodent brain of $1.5 \mathrm{~kg}$ ? We can do the math to find out: the brain would have only 19 billion neurons, far fewer than our 86 billion-and the brain would probably be able to do much less. Now let us invert the question: how big would a rodent brain have to be to have 86 billion neurons like ours? Well, really big. It would weigh over $30 \mathrm{~kg}$ ! This imaginary rodent would need a body of over $80 \mathrm{t}$ to carry a brain this bigthis is as much as 20 elephants together, as shown in Figure 3! Such a giant rodent could never exist: its brain would be crushed under its own weight (remember that the brain does not have a structure inside itself to support it, like a hard skeleton). No wonder such a huge rodent has never appeared in the history of life.

Other types of mammals studied so far-bats, insectivores, carnivores, marsupials, and cetaceans-have a lot in common, but also many differences. It seems that nature has many different recipes, or rules, for building brains. There is a lot of diversity in brains, just like different types of animals 


\section{FIGURE 3}

If there were a rodent with as many neurons as a human has - 86 billionits brain would weigh over $30 \mathrm{~kg}$. This means that this hypothetical rodent would need a body of $80 t$ to carry the super heavy brain. To get an idea of what this super rodent would have to look like, imagine putting it on a scale: it would weigh the same as 20 elephants!

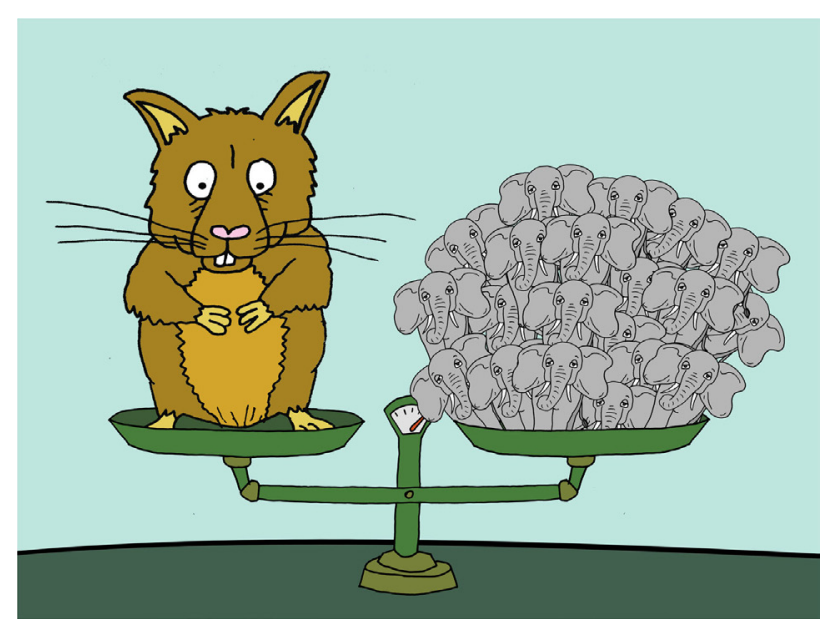

FIGURE 3

look different on the outside. But primates are the ones that fit the most neurons in the cerebral cortex, the "thinking" part of the brain, compared with other species that have similar size brains. This does not mean everything is different in primate brains. Remember that all animals share common grand-grand-grand-grandparents from many years back, and some brain rules are shared. Just one quick example: the rule relating the number of glial cells (remember them? See Figure 1) to brain size is the same for all groups of mammals. Because this is common to all mammals, we think it must be very important in order for the brain to work well.

All of information about brain rules is important for many reasons. The human brain is not the largest of all brains. For instance, the largest land mammal, the elephant, has a cerebral cortex that weighs twice as much as the human cortex. However, because the brains of different animals are built in different ways, the elephant's gigantic cortex has only a third of the neurons that humans have in their cerebral cortex $[3,4]$. The lesson here is that size may be important, but it is far from everything when it comes to comparing brains. Because of the different "recipes" that nature uses to build brains, comparing primate brains to rodent brains is like comparing apples to oranges. Besides, if we want to know about the abilities of an animal, the number of neurons should matter much more than the size of the brain. That is because neurons are the cells that process all the information the brain gets and turns it into action. So having more neurons is probably better, for brain ability, at least-as long as the brain does not become too big!

\section{REFERENCES}

1. Herculano-Houzel, S., and Lent, R. 2005. Isotropic fractionator: a simple, rapid method for the quantification of total cell and neuron numbers in the brain. J. Neurosci. 25(10):2518-21. doi:10.1523/JNEUROSCl.4526-04.2005 
2. Azevedo, F. A., Carvalho, L. R., Grinberg, L. T., Farfel, J. M., Ferretti, R. E., Leite, R. E., et al. 2009. Equal numbers of neuronal and nonneuronal cells make the human brain an isometrically scaled-up primate brain. J. Comp. Neurol. 513(5):532-41. doi:10.1002/cne.21974

3. Herculano-Houzel, S., Manger, P. R., and Kaas, J. H. 2014. Brain scaling in mammalian evolution as a consequence of concerted and mosaic changes in numbers of neurons and average neuronal cell size. Front. Neuroanat. 8:77. doi:10.3389/fnana.2014.00077

4. Herculano-Houzel, S., Avelino-de-Souza, K., Neves, K., Porfírio, J., Messeder, D., Mattos Feijó, L., et al. 2014. The elephant brain in numbers. Front. Neuroanat. 8:46. doi:10.3389/fnana.2014.00046

SUBMITTED: 09 June 2016; ACCEPTED: 28 April 2017;

PUBLISHED ONLINE: 22 May 2017.

EDITED BY: Robert T. Knight, University of California, Berkeley, USA

CITATION: Neves K, daCunha F and Herculano-Houzel S (2017) What Are Different Brains Made Of? Front. Young Minds 5:21. doi:10.3389/frym.2017.00021

CONFLICT OF INTEREST STATEMENT: The authors declare that the research was conducted in the absence of any commercial or financial relationships that could be construed as a potential conflict of interest.

COPYRIGHT () 2017 Neves, daCunha and Herculano-Houzel. This is an open-access article distributed under the terms of the Creative Commons Attribution License (CC BY). The use, distribution or reproduction in other forums is permitted, provided the original author(s) or licensor are credited and that the original publication in this journal is cited, in accordance with accepted academic practice. No use, distribution or reproduction is permitted which does not comply with these terms.

\section{REVIEWED BY}

\section{RIVERSIDE ELEMENTARY SCHOOL, 9-10 YEARS OLD}

About Riverside Elementary School: Riverside Elementary School serves children from prekindergarten through fifth grade in Princeton, NJ, USA. Our diverse student body includes children from more than 23 different countries, and we all love to learn about brains! We also have a science lab, a courtyard with frogs and box turtles, a team of dedicated teachers and support staff, and a great principal who always supports new opportunities for learning. Fourth grade students are either in Ms. Levy's or Mr. McGovern's classroom, and Mr. Eastburn is their teacher in the science lab.

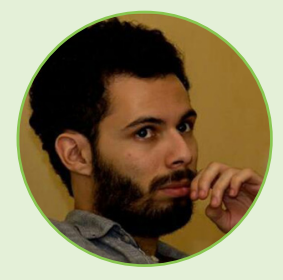

\section{AUTHORS}

\section{KLEBER NEVES}

I am Kleber Neves, a PhD candidate at the Universidade Federal do Rio de Janeiro, in Brazil. My research interests go from the evolution of brain and cognitive abilities - what is it about 


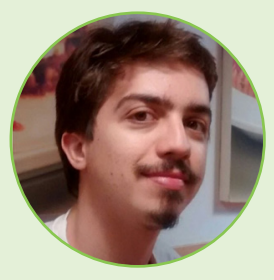

the brain that makes animal behavior more or less complex? - to networks and computational models - applied to the development of the brain and other systems. I also love teaching and thinking about education: from how people learn to how our schools and universities could be better. If I am not working, I might be reading, making computer games, writing, playing guitar and singing (not that well) or sometimes in a stage, acting. *kleber.na@gmail.com

\section{FELIPE DACUNHA}

I am Felipe Barros da Cunha, a PhD candidate at the University of Lethbridge. My primary interest is to understand, through comparative neuroscience, how the brains of different species change, and how this relates to animal behavior. One of the topics of my PhD is to comprehend the differences in brain anatomy between monogamous and polygamous species. During my spare time, I enjoy hiking to explore new places and sometimes I try to play pandeiro, a Brazilian instrument which you can make a bunch of sounds.

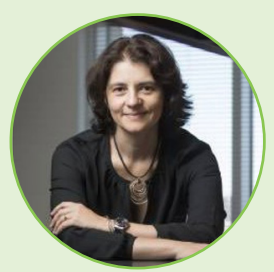

\section{SUZANA HERCULANO-HOUZEL}

I am Suzana Herculano-Houzel, a Brazilian-born biologist and neuroscientist working as a professor at Vanderbilt University in the USA. My favorite topic is diversity: how can brains become so different across animal species, and also across individuals, while retaining a number of similarities? That is, how come bird brains look so different from mammalian brains in some ways, and yet in others, look and function similarly? And, most of all, what difference does it make to have brains made in different ways? I am also a science writer. What I love most about brain research is that it applies everywhere we look, in all moments of our daily lives. 